\title{
ASSESSING HYPERSPECTRAL VEGETATION INDICES FOR ESTIMATING LEAF CHLOROPHYLL CONCENTRATION OF SUMMER BARLEY
}

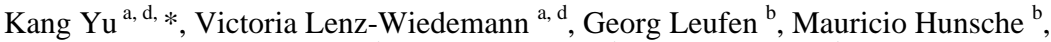 \\ Georg Noga ${ }^{b}$, Xinping Chen ${ }^{c, d}$, Georg Bareth ${ }^{\mathrm{a}, \mathrm{d}}$ \\ ${ }^{a}$ Institute of Geography (GIS \& Remote Sensing Group), University of Cologne, 50923 Köln \\ ${ }^{\mathrm{b}}$ INRES- Horticultural Science, University of Bonn, 53121 Bonn \\ c College of Resources \& Environmental Sciences, China Agricultural University, 100094 Beijing, China \\ ${ }^{\mathrm{d}}$ International Center for Agroinformatics and Sustainable Development (www.icasd.org), Germany \\ * Corresponding author. Tel.: +49 0221470 6551; fax: +49 02214701638. \\ E-mail address: kyu@uni-koeln.de
}

Commission VII, WG VII/3

\begin{abstract}
KEY WORDS: Hyperspectral Remote Sensing, Vegetation Index (VI), Leaf Chlorophyll Concentration (LCC), Red Edge, Summer Barley
\end{abstract}

\begin{abstract}
:
Hyperspectral reflectance data were collected at 7 critical phenological stages in a summer barley field with 7 varieties in 2010 , without artificial nutrient gradients. Throughout the range of 350 to $1800 \mathrm{~nm}$, all possible two-bands combinations for the simple ratio $(\mathrm{SR}=\mathrm{Rj} / \mathrm{R} i)$ and the normalized difference vegetation index (NDVI= $(\mathrm{R} j-\mathrm{R} i) /(\mathrm{Rj}+\mathrm{R} i))$ were evaluated using linear regression analysis against the leaf chlorophyll concentration (LCC). This study introduces a more comprehensive way of using the "correlation matrix" method for selecting sensitive bands and shows that in this way the newly selected SRs may outperform the NDVIs for estimating LCC. With this method, the selection of two-bands combinations for the SRs and NDVIs improved the performance for estimating LCC. Both the new SR $(734,629)$ and the new NDVI $(667,740)$ explained more than $74 \%$ of the variation in LCC across all the growth stages and all varieties. Compared with published indices, newly selected SRs and NDVIs improved the predictive ability for LCC. The most significant improvement was observed with increasing of $\mathrm{R}^{2}$ values by $13 \%$ for SR and $6 \%$ for NDVI. The overall performances of both newly selected indices and published indices were significantly influenced by the varieties. Moreover, Ultraviolet, Violet and Blue bands are more effective for estimating the LCC for a single variety, whereas Red-edge bands are more effective for that across all varieties. Therefore, a conclusion can be drawn that selecting twobands combinations significantly improves the capability of SRs and NDVIs for estimating the LCC of summer barley.
\end{abstract}

\section{INTRODUCTION}

The absolute and relative leaf chlorophyll concentrations (LCC) provide valuable information about the physiological status and the photosynthetic potential of plants (Chappelle et al., 1992; Gitelson et al., 2003). Studies have shown that reflectance measurements can be used to non-destructively and quickly assess the leaf chlorophyll concentration in many crops (Yoder and Pettigrew-Crosby, 1995; Blackburn, 1998; Daughtry et al., 2000; Carter and Knapp, 2001; Haboudane et al., 2002; Gitelson et al., 2003; Zhao et al., 2003; Zhao et al., 2005a). However, almost all these studies were conducted in controlled environmental conditions with artificial $\mathrm{N}$ nutrient gradients, and some plants even faced $\mathrm{N}$ deficiency as well as stress caused by disease, insects and other nutrients deficiency. It is noted that not only $\mathrm{N}$ deficiency causes reflectance increase in the visible spectral region (Read et al., 2002), but also other stresses may result in an increased reflectance due to the reduced amount of chlorophyll (Carter and Knapp, 2001). Therefore, the determination of leaf chlorophyll concentration in one field environment without an artificial nutrient gradient is required for improving our knowledge of the relationship between the hyperspectral reflectance data and the investigated plant physiological variables.
The most popular way for assessing LCC is to establish a quantitative relationship between the LCC and a vegetation index (VI). In the last decades numerous VIs have been developed for estimating biomass (Rouse et al., 1974), LAI (Jordan, 1969; Asrar et al., 1985; Haboudane et al., 2004), LCC (Chappelle et al., 1992; Haboudane et al., 2002) and $\mathrm{N}$ concentration (Peñuelas et al., 1994; Read et al., 2002). Two categories of the most widely used VIs are the simple ratios (SR, or called ratio vegetation indices, RVI) and the normalized difference vegetation indices (NDVI, or called NDI). Based on the idea, recently, the "correlation matrix" (similar to confusion matrix) method is often used for selecting the best performing VIs as reported for winter wheat (Hansen and Schjoerring, 2003; Li et al., 2010), rice (Stroppiana et al., 2009; Tian et al., 2011), corn, soybean, cotton and potato (Thenkabail et al., 2000) and grass (Darvishzadeh et al., 2008). This method identifies new VIs by combining randomly two or more wavebands throughout all the wavelength range of spectrometers (normally ranges from 350 up to $2500 \mathrm{~nm}$ ) and evaluates the correlations with the variables of interest (LCC, LAI, N concentration, etc.). Using this method, Li et al. (2010) developed a "NDVI-like" index NDVI $(365,410)$ that was linearly related to plant $\mathrm{N}$ concentration of winter wheat across sites, years and growth stages with a coefficient of determination $\left(\mathrm{R}^{2}\right)$ of 0.58 . However,

\footnotetext{
* Corresponding author
} 
Darvishzadeh et al. (2008) found that the best performing "NDVI-like" index NDVI $(547,554)$ could explain only $25 \%$ of the LCC variation in grass. The same method was used to select the best performing VIs in the aforementioned two studies, while results appear to be inconsistent in different species. Moreover, Stroppiana et al. (2009) derived a NDVI (503, 483) with the blue and green wavebands that was logarithmically correlated to plant $\mathrm{N}$ concentration of rice $\left(\mathrm{R}^{2}=\right.$ 0.65). And Tian et al. (2011) derived a NDVI $(533,565)$ and a SR $(533,565)$ with the same wavelengths and both with a linear relationship to leaf $\mathrm{N}$ concentration of rice $\left(\mathrm{R}^{2}=0.76\right)$. These results of preliminary studies indicate that not only the performances of the best VIs for different species differ greatly using the "correlation matrix" method, but also the sensitive wavelengths derived for these VIs differ greatly, even for the same crops. All above mentioned studies have shown the great potential of VIs for assessing plant physiological properties. However, as a consequence of different measurement conditions, some degree of disagreement exists in the selection of wavebands (Hansen and Schjoerring, 2003). To our knowledge, still no literatures on field grown summer barley have been found using the "correlation matrix" method to derive VIs for estimating the leaf chlorophyll status.

Therefore, the main objective of this study is to evaluate all the possible two-bands combinations in the range of 350-1800 nm as both the SR and NDVI for estimating the LCC in a summer barley field without any artificial nutrient gradients.The collection of spectral reflectance and crop data was conducted across all the growth stages to consider canopy variations due to growth stages and environmental factors.

\section{MATERIALS AND METHODS}

\subsection{Study Area and Experimental Design}

The experiment area is located at the Institute of Crop Science and Resource Conservation (INRES-Horticultural Science, latitude $50.72999^{\circ}$, longitude $7.0754^{\circ}$; sandy loam soil; soil Nmin value of $20 \mathrm{~kg} \mathrm{~N} \mathrm{ha}^{-1} ; 70 \mathrm{~m}$ a.s.l., annual average precipitation of $669 \mathrm{~mm}$, average temperature of $10.3{ }^{\circ} \mathrm{C}$ ), University of Bonn, Germany. A trial with 7 barley (Hordeum vulgare) varieties was conducted from March to July 2010. The experiment was organized as a completely randomized block with 6 replications and a plot size of $6 \mathrm{~m}^{2}(1.5 \times 4 \mathrm{~m})$ for each variety and treatment. 7 commercial varieties of malting barley (Belana, Marthe, Scarlett, Iron, Sunshine, Barke and Bambina) were sown with a density of 320 seeds per square meter. All plots were fertilized directly after sowing with ammonium nitrate $\left(\mathrm{NH}_{4}-\mathrm{N}\right)$ at a rate of $100 \mathrm{~kg} \mathrm{~N} \mathrm{ha}^{-1}$. For each variety, 3 replications were sprayed with fungicides over the whole experimental period, whereas the other 3 replications were not sprayed with fungicides after the plants reached the phenological stage 39 according to the $\mathrm{BBCH}$ code (Lancashire et al., 1991). The fungicides have a protective and/or curative effect against the most harmful pathogens in cereals.

\subsection{Canopy Spectral Measurements}

Canopy spectral reflectance was weekly measured with the ASD QualitySpec ${ }^{\circledR}$ Pro and FieldSpec ${ }^{\circledR} \quad 3$ spectrometers (Analytical Spectral Devices Inc., Boulder, CO, USA). The measurements were carried out between 10 am and $14 \mathrm{pm}$ local time under sunshine and cloudless conditions throughout the growing season, with a distance of $1 \mathrm{~m}$ above canopy. The ASD
QualitySpec ${ }^{\circledR}$ Pro spectrometer is configured with Visible and NIR spectral ranges and a $1.4 \mathrm{~nm}$ sampling interval between 350 and $1050 \mathrm{~nm}$ and a $2 \mathrm{~nm}$ sampling interval between 1000 and $1800 \mathrm{~nm}$ with a $3 \mathrm{~nm}$ and $10 \mathrm{~nm}$ spectral resolution at 700 $\mathrm{nm}$ and $1400 \mathrm{~nm}$, respectively. Slightly different, the ASD FieldSpec ${ }^{\circledR} 3$ spectrometer is configured with a spectral range from $350 \mathrm{~nm}$ to $2500 \mathrm{~nm}$, a $1.4 \mathrm{~nm}$ sampling interval between 350 and 1050 a $2 \mathrm{~nm}$ sampling interval between 1000 and 2500 $\mathrm{nm}$, and with a $3 \mathrm{~nm}$ spectral resolution at $700 \mathrm{~nm}, 10 \mathrm{~nm}$ spectral resolution at 1400 and $2100 \mathrm{~nm}$. The field of view is 25 degrees. Calibration measurements of dark current and reflectance of a white standard panel made out of $\mathrm{BaSO}_{4}$ were taken before the canopy reflectance measurements. Per plot, 6 canopy spectra were measured and then averaged for each plot.

\subsection{Leaf Chlorophyll Measurements}

Samples for determining chlorophyll content were collected randomized at the end of May up to July at weekly intervals, with 10 whole flag leaves from all the plots. The leaf samples were lyophilized immediately after collecting, grounded and stored in the dark at room temperature. Chlorophyll content of each sample was extracted from the $50 \mathrm{mg}$ lyophilized material with $5 \mathrm{ml}$ methanol and filled up to $25 \mathrm{ml}$. After extraction, the absorbance of extracts was measured at $665 \mathrm{~nm}$ (A665) and 650 nm (A650) with a UV-VIS spectrophotometer (Perkin-Elmer, Lambda 5, Massachusetts, USA). The chlorophyll concentration $(\mathrm{Chl})$ was calculated with the following equations (Eq. 1):

$$
C h l=\frac{(25.5 * A 650+4.0 * A 665) * 25}{D M W * 1000}
$$

where $D M W$ is the dry matter weight (g) of each leaf sample.

\subsection{Data Analysis}

Six spectra of each plot were averaged and preprocessed in Microsoft Office Excel 2007. Subsequently, the correlation analysis (Pearson correlation) and "contour map" processing were carried out using the MATLAB 7.10.0 (R2010a) software (MathWorks, Inc.). Randomly, 15 published SRs and 15 published NDVIs (listed in Table 1), composed of different and diverse bands combinations were selected for evaluating and comparing the new ones identified in our study. The equations for selecting new VIs of two-bands ( $\mathrm{Rj}$ and $\mathrm{R} i$ ) combinations were the simple ratio index and the normalized difference vegetation index (Eq. 2 and 3).

$$
\begin{aligned}
& S R=R_{j} / R_{i} \\
& N D V I=\frac{R_{j}-R_{i}}{R_{j}+R_{i}}
\end{aligned}
$$

\section{RESULTS}

\subsection{Relationship between Published VIs and LCC}

Across all 7 varieties, the best performing published SR and NDVI explained $71 \%$ and $74 \%$ of the variation in LCC, respectively. For a single variety, the best performing published SR and NDVI explained $83 \%$ and $85 \%$ of the LCC variation, respectively, for Scarlett and Bambina (Table 2). It is shown 
that the SRs 1-11 and 15 explained no more than $60 \%$ of the LCC variation for each single variety or for that all varieties (data not shown). Published NDVIs in most cases outperformed the published SRs and are more consistent with earlier studies. However, for chlorophyll specially developed MTCI (NDVI 8) by Dash and Curran (2004) explained only $48 \%$ of the LCC variation for all varieties (data not shown). This means VIs selected in one situation may not suitable for another situation even when using the same method and for the same crops.

Table 1. Published VIs evaluated in this study.

\begin{tabular}{|c|c|}
\hline Index and Equation & Reference \\
\hline \multicolumn{2}{|l|}{ SR 1-15 } \\
\hline $\mathrm{R}_{800} / \mathrm{R}_{675}$ & Jordan (1969) \\
\hline $\mathrm{R}_{800} / \mathrm{R}_{680}$ & Blackburn (1998) \\
\hline $\mathrm{R}_{800} / \mathrm{R}_{635}$ & Blackburn (1998) \\
\hline $\mathrm{R}_{800} / \mathrm{R}_{470}$ & Blackburn (1998) \\
\hline $\mathrm{R}_{801} / \mathrm{R}_{670}$ & Daughtry et al. (2000) \\
\hline $\mathrm{R}_{801} / \mathrm{R}_{550}$ & Daughtry et al. (2000) \\
\hline $\mathrm{R}_{810} / \mathrm{R}_{560}$ & Xue et al. (2004) \\
\hline $\mathrm{R}_{750} / \mathrm{R}_{700}$ & Gitelson and Merzlyak (1996) \\
\hline $\mathrm{R}_{750} / \mathrm{R}_{550}$ & Gitelson and Merzlyak (1996) \\
\hline $\mathrm{R}_{750} / \mathrm{R}_{710}$ & Zarco-Tejada et al. (2001) \\
\hline $\mathrm{R}_{750} / \mathrm{R}_{705}$ & Sims and Gamon (2002) \\
\hline $\mathrm{R}_{675} / \mathrm{R}_{700}$ & Chappelle et al. (1992) \\
\hline $\mathrm{R}_{415} / \mathrm{R}_{685}$ & Read et al. (2002) \\
\hline $\mathrm{R}_{415} / \mathrm{R}_{695}$ & Read et al. (2002) \\
\hline $\mathrm{R}_{415} / \mathrm{R}_{710}$ & Read et al. (2002) \\
\hline \multicolumn{2}{|l|}{ NDVI 1-15 } \\
\hline$\left(\mathrm{R}_{1220}-\mathrm{R}_{710}\right) /\left(\mathrm{R}_{1220}+\mathrm{R}_{710}\right)$ & Zhu et al. (2007) \\
\hline$\left(\mathrm{R}_{800}-\mathrm{R}_{680}\right) /\left(\mathrm{R}_{800}+\mathrm{R}_{680}\right)$ & Blackburn (1998) \\
\hline$\left(\mathrm{R}_{800}-\mathrm{R}_{635}\right) /\left(\mathrm{R}_{800}+\mathrm{R}_{635}\right)$ & Blackburn (1998) \\
\hline$\left(\mathrm{R}_{800}-\mathrm{R}_{470}\right) /\left(\mathrm{R}_{800}+\mathrm{R}_{470}\right)$ & Blackburn (1998) \\
\hline$\left(\mathrm{R}_{680}-\mathrm{R}_{430}\right) /\left(\mathrm{R}_{680}+\mathrm{R}_{430}\right)$ & Peñuelas et al. (1994) \\
\hline$\left(\mathrm{R}_{801}-\mathrm{R}_{550}\right) /\left(\mathrm{R}_{801}+\mathrm{R}_{550}\right)$ & Daughtry et al. (2000) \\
\hline$\left(\mathrm{R}_{801}-\mathrm{R}_{670}\right) /\left(\mathrm{R}_{801}+\mathrm{R}_{670}\right)$ & Daughtry et al. (2000) \\
\hline$\left(\mathrm{R}_{750}-\mathrm{R}_{710}\right) /\left(\mathrm{R}_{710}-\mathrm{R}_{680}\right)$ & Dash and Curran (2004) \\
\hline$\left(\mathrm{R}_{750}-\mathrm{R}_{705}\right) /\left(\mathrm{R}_{750}+\mathrm{R}_{705}\right)$ & Sims and Gamon (2002) \\
\hline$\left(\mathrm{R}_{750}-\mathrm{R}_{445}\right) /\left(\mathrm{R}_{705}-\mathrm{R}_{445}\right)$ & Sims and Gamon (2002) \\
\hline$\left(\mathrm{R}_{531}-\mathrm{R}_{570}\right) /\left(\mathrm{R}_{531}+\mathrm{R}_{570}\right)$ & Sims and Gamon (2002) \\
\hline$\left(\mathrm{R}_{550}-\mathrm{R}_{531}\right) /\left(\mathrm{R}_{550}+\mathrm{R}_{531}\right)$ & Gamon et al. (1992) \\
\hline$\left(\mathrm{R}_{573}-\mathrm{R}_{440}\right) /\left(\mathrm{R}_{573}+\mathrm{R}_{440}\right)$ & Hansen and Schjoerring (2003) \\
\hline$\left(\mathrm{R}_{565}-\mathrm{R}_{533}\right) /\left(\mathrm{R}_{565}+\mathrm{R}_{533}\right)$ & Tian et al. (2011) \\
\hline$\left(\mathrm{R}_{503}-\mathrm{R}_{483}\right) /\left(\mathrm{R}_{503}+\mathrm{R}_{483}\right)$ & Stroppiana et al. (2009) \\
\hline
\end{tabular}

\subsection{Selecting New VIs for Estimating LCC}

The "correlation matrix" was carried out with all the possible two-bands combinations throughout 350 to $1800 \mathrm{~nm}$ range using a comprehensive computing method and contour maps of $\mathrm{R}^{2}$ values were subsequently plotted versus the corresponding wavelengths, as shown in Figure 1 (a-h for SRs, i-p for NDVIs). The wide variance of $R^{2}$ values ranging from 0 to 0.90 indicates that the large difference exists in the strength of the associations between new VIs and LCC in different varieties.

In this study, we improved the "correlation matrix" method for the SRs calculated with Eq. (2) by considering both possibilities of combining the wavelengths, $j>i$ and $j<i$, namely, above the diagonal (AD, upper left) and below the diagonal (BD, lower right) as shown in Figure 1. This was not addressed in earlier studies, which usually focused on one case only, either $j>i$ or $j$ $<i$, as presented in many studies (Thenkabail et al., 2000; Hansen and Schjoerring, 2003; Li et al., 2010; Tian et al., 2011) For the SRs, the two cases $j>i$ and $j<i$ (above and below the diagonal, respectively, $\mathrm{AD}$ and $\mathrm{BD}$ ) differed greatly from each other in the variation of correlation strength. In the case of $j>i$ (AD), "hot spots" with highest $\mathrm{R}^{2}$ values mainly appeared in the VIS range above the diagonal, whereas a shift to longer wavelengths in the NIR range occurred below the diagonal when $j<i$ (BD). Results visually reveal that SRs of the wavelengths at $350-450 \mathrm{~nm}$ paired with the wavelengths at 400 500 or $600-680 \mathrm{~nm}$ when $j>i$, and SRs of the wavelengths at $750-1000 \mathrm{~nm}$ paired with the wavelengths at $600-700 \mathrm{~nm}$ when $j<i$, are the best indicators for estimating LCC. For each single variety and across all varieties, the best SRs with the highest $\mathrm{R}^{2}$ values in Figure 1 were listed in Table 2. The best performing new SRs explained $74 \%$ of the LCC variation across all varieties and $70 \%$ to $88 \%$ of the LCC variation for every single variety. Compared with the published SRs, our newly selected SRs improved the capability for estimating LCC not only for a single variety but also for that across all varieties. The most significant improvement was observed for the variety Marthe where $\mathrm{R}^{2}$ increased by $13 \%$ (Table 2 ).

In contrast to the SRs, the contour maps of the NDVIs shown almost no difference in the variation of correlation strength between the two cases of $j>i$ and $j<I$, while yielded the symmetrical images (Fig. 1). Hot spots of the highest $\mathrm{R}^{2}$ values

Table 2. Best newly selected SRs/ NDVIs and best published SRs/ NDVIs for estimating LCC in different varieties.

\begin{tabular}{|c|c|c|c|c|c|c|}
\hline \multirow{2}{*}{ Variety } & \multicolumn{4}{|c|}{ Newly Selected SRs/ NDVIs } & \multicolumn{2}{|c|}{ Best Published SRs/ NDVIs } \\
\hline & Best SR/ NDVI $(i, j)$ & Band & $\mathrm{R}^{2}$ & Location* & Index & $\mathrm{R}^{2}$ \\
\hline Belana & SR $(406,487)$ & Violet, Blue & 0.86 & $\mathrm{AD}$ & SR 12 & 0.81 \\
\hline Marthe & SR $(394,443)$ & Violet, Blue & 0.79 & $\mathrm{AD}$ & SR 12 & 0.66 \\
\hline Scarlett & SR $(431,455)$ & Blue, Blue & 0.87 & $\mathrm{AD}$ & SR 12 & 0.83 \\
\hline Iron & SR $(1006,667)$ & NIR, Red & 0.70 & $\mathrm{BD}$ & SR 12 & 0.65 \\
\hline Sunshine & SR $(351,680)$ & Ultraviolet, Red & 0.75 & $\mathrm{AD}$ & SR 12 & 0.74 \\
\hline Barke & SR $(421,428)$ & Blue, Blue & 0.78 & $\mathrm{AD}$ & SR 12 & 0.75 \\
\hline Bambina & SR $(356,680)$ & Ultraviolet, Red & 0.88 & $\mathrm{AD}$ & SR 12 & 0.78 \\
\hline All & SR $(734,629)$ & Red-edge, Red & 0.74 & $\mathrm{BD}$ & SR 12 & 0.71 \\
\hline Belana & NDVI $(406,487),(487,406)$ & Violet, Blue & 0.85 & $\mathrm{AD}, \mathrm{BD}$ & NDVI 2, 3, 7 & 0.81 \\
\hline Marthe & NDVI $(394,434),(434,394)$ & Violet, Blue & 0.78 & $\mathrm{AD}, \mathrm{BD}$ & NDVI 14 & 0.73 \\
\hline Scarlett & NDVI $(431,455),(455,431)$ & Blue, Blue & 0.87 & $\mathrm{AD}, \mathrm{BD}$ & NDVI 5 & 0.81 \\
\hline Iron & NDVI $(679,748),(748,679)$ & Red, Red-edge/ NIR & 0.70 & $\mathrm{AD}, \mathrm{BD}$ & NDVI 2, 7 & 0.69 \\
\hline Sunshine & NDVI $(390,430),(430,390)$ & Violet, Blue & 0.71 & $\mathrm{AD}, \mathrm{BD}$ & NDVI 2, 7 & 0.71 \\
\hline Barke & NDVI $(421,428),(428,421)$ & Blue, Blue & 0.78 & $\mathrm{AD}, \mathrm{BD}$ & NDVI $2,3,7$ & 0.76 \\
\hline Bambina & NDVI $(679,934),(934,679)$ & Red, NIR & 0.86 & $\mathrm{AD}, \mathrm{BD}$ & NDVI 2, 7 & 0.85 \\
\hline All & NDVI $(667,740),(740,667)$ & Red, Red-ege/ NIR & 0.74 & $\mathrm{AD}, \mathrm{BD}$ & NDVI $2,3,7$ & 0.74 \\
\hline
\end{tabular}

*, $\mathrm{AD}$, above the diagonal in contour maps; $\mathrm{BD}$, below the diagonal in contour maps. 

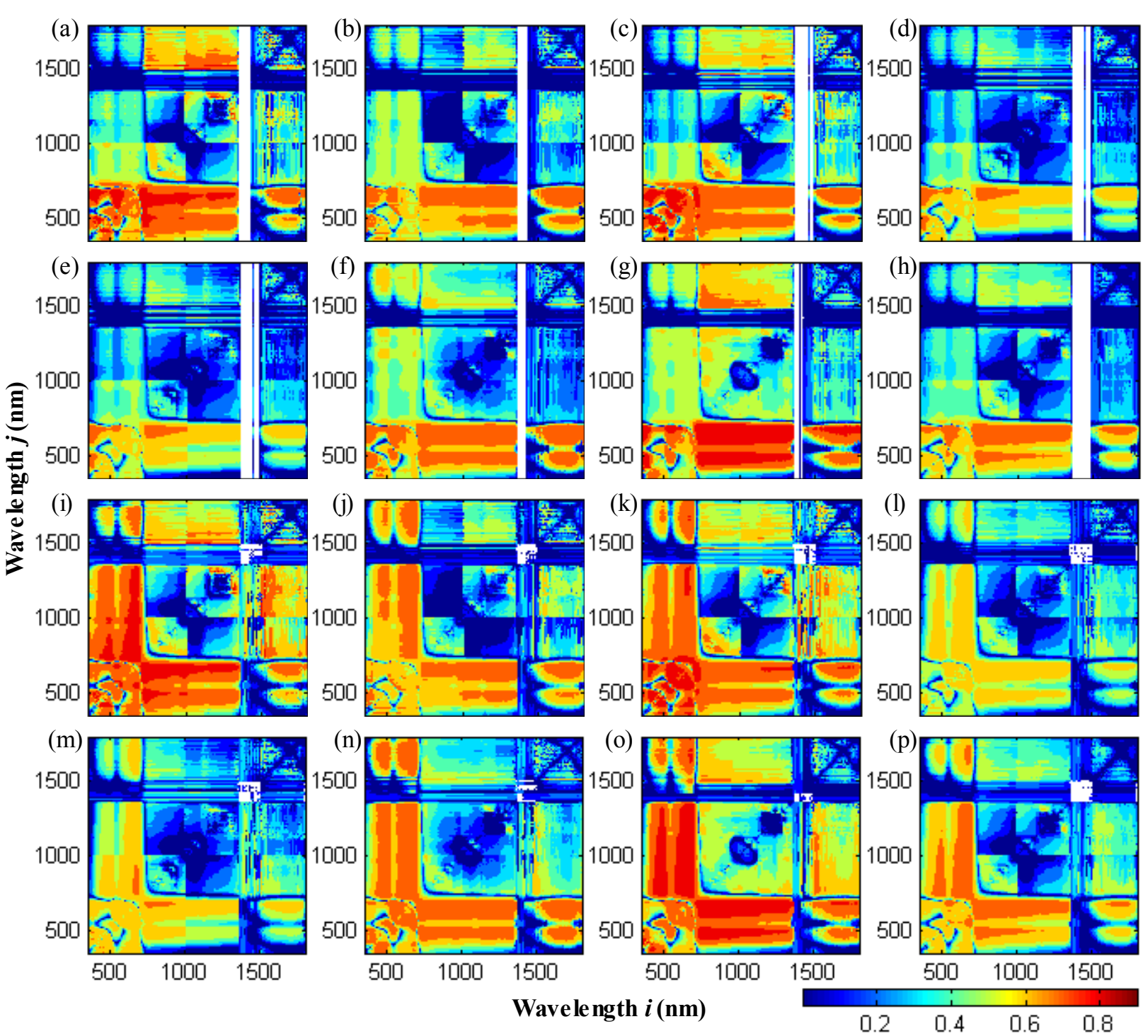

Fig. 1. Contour maps showing the values of $R^{2}$ for the relationships between LCC and SRs (a-h) and NDVIs (i-p) composed of random two-bands combinations throughout the range of 350 to $1800 \mathrm{~nm}$ across all growth stages for each single variety (a-g/ i-o stand for Belana, Marthe, Scarlett, Iron, Sunshine, Barke and Bambina respectively) and for all varieties (h and p).

centered where, on one hand, the wavelengths at 420-500 $\mathrm{nm}$ paired with the wavelengths at $380-420 \mathrm{~nm}$ in the VIS; on the other hand, the wavelengths at $650-700 \mathrm{~nm}$ paired with the wavelengths at $740-1000 \mathrm{~nm}$ in the NIR. The best NDVIs with highest $\mathrm{R}^{2}$ values in Figure 1 were listed in Table 2 . The best performing new NDVIs explained $74 \%$ of the LCC variation across all varieties and $70 \%$ to $87 \%$ of the LCC variation for every single variety. Compared with the published NDVIs, our newly selected NDVIs improved the predictive ability for 6 individual varieties. The most significant improvement was observed for Scarlett where $\mathrm{R}^{2}$ increased by $6 \%$ (Table 2 ).

\section{DISCUSSION}

The published SRs 1-11 and 15 explained no more than $60 \%$ of the LCC variation for each single variety and for that across all varieties in this study (data not shown). But these SRs were reported somewhere explained more than $90 \%$ of the variation in chlorophyll (Gitelson and Merzlyak, 1996; Blackburn, 1998; Daughtry et al., 2000; Read et al., 2002), and $85 \%$ of the variation in leaf $\mathrm{N}$ accumulation (Xue et al., 2004). The SR 11 explained $61 \%$ of the variation in total LCC across several species as reported by Sims and Gamon (2002), but explained only $52 \%$ of the LCC variation across the 7 varieties in this study. Notably, SR 12 explained $71 \%$ of the variation in LCC across all varieties, and more than $75 \%$ of that for a single variety (i.e. Belana, Scarlett, Barke and Bambina). This is consistent with the study by Chappelle et al. (1992) who found that $93 \%$ of the variation in chlorophyll concentration of soybean leaves was explained by the SR 12. The varied performance of these published SRs in present study indicates that some published SRs cannot provide a very constant performance for estimating LCC of different species in different conditions.

For this reason, a large number of SRs were proposed and used for chlorophyll or $\mathrm{N}$ estimation based on the approaches of identifying sensitive bands (Chappelle et al., 1992; Blackburn, 1998; Zarco-Tejada et al., 2001; Zhao et al., 2003; Zhao et al., $2005 \mathrm{~b}$ ) or the method of "correlation matrix" (Li et al., 2010; Tian et al., 2011). The advantages of the $\mathrm{R}^{2}$ matrix plots are that 
they provide a quick overview of thousands of wavelengths combinations and make it possible to detect wavelengths of interest (Hansen and Schjoerring, 2003). Our results indicate that, in present study, new SRs of the wavelengths at 350-450 $\mathrm{nm}$ paired with the wavelengths at $400-500 \mathrm{~nm}$ or $600-680 \mathrm{~nm}$ $(j>i)$, and the wavelengths at $750-1000 \mathrm{~nm}$ paired with the wavelengths at $600-700 \mathrm{~nm}(j<i)$ are the best indicators for estimating LCC for each single variety and for that across all varieties. This not only confirms the empirical bands for estimating chlorophyll or $\mathrm{N}$ concentration but also reveals that several SRs (Ultraviolet bands paired with Red bands, Violet paired with Blue, or Blue paired with Blue, Table 2) can also be very effective for estimating LCC. Ultraviolet, Violet and Blue bands are more efficient for single varieties, whereas Red-edge bands are more effective when across all the varieties. Compared with published SRs, the best new SRs all improved the predictive ability for LCC. Especially, the most significant improvement was observed for the variety Marthe where the $\mathrm{R}^{2}$ value increased by $13 \%$ with the new SR $(394,443)$.

Published NDVIs in most cases outperformed published SRs which were evaluated in this study. The published NDVIs 13, 14 and 15 were all proposed using the similar method as used in present study: for chlorophyll concentration of wheat (Hansen and Schjoerring, 2003), for leaf $\mathrm{N}$ concentration of rice (Tian et al., 2011) and for plant N concentration of rice (Stroppiana et al., 2009). However, only NDVI 14 showed a comparative performance for estimating the LCC in this study $\left(\mathrm{R}^{2}=0.58\right.$ 0.76 , data not shown). This means that the selection of NDVIs is also species-specific, as well as that of SRs. Our newly selected NDVIs also improved the capability for estimating LCC. The most significant improvement was observed for Scarlett where the $\mathrm{R}^{2}$ value increased by $6 \%$ with the new NDVI $(431,455)$ (Table 2). New NDVIs of the wavelengths at 420-500 nm paired with the wavelengths at $380-420 \mathrm{~nm}$, and the wavelengths at $650-700 \mathrm{~nm}$ paired with the wavelengths at $740-1000 \mathrm{~nm}$ are the best indicators for estimating LCC for each single variety and across all varieties. Hansen and Schjoerring (2003) reported that the bands for predicting LCC were exclusively found in the VIS, mainly in the Blue region paired with a Green or a Red band. However, in our results the "hot spots" of NDVIs vs LCC are mainly in the Blue bands paired with Blue or Violet bands (Table 2). Furthermore, Ultraviolet, Violet and Blue bands can play very effective roles for estimating LCC in each single variety, whereas Red-edge bands are more effective for that across all varieties. This is consistent with aforementioned results of selecting SRs.

Although the published NDVIs performed better in most cases in this study than the published SRs, our newly selected SRs outperformed both the newly selected NDVIs and the best published NDVIs. This reveals that the SRs identified with the more comprehensive computing method of "correlation matrix" may have a better potential of estimating LCC than the NDVIs. Generally, in earlier studies, the selection of SRs was conducted mainly focused on one case of the probability (either $j>i$ or $j<$ i) and thus only "half" of the contour map was generated. For instance, Tian et al. (2011) evaluated both SRs and NDVIs to estimate the leaf $\mathrm{N}$ concentration of rice and found that the best selected SR and NDVI have the same bands combination and the same capability $\left(\mathrm{R}^{2}\right)$. This interesting phenomenon can be also seen in our results (Table 2). But in a study for estimating plant N concentration, Li et al. (2010) reported that a NDVI (365, 410) was the best indicator, rather than a SR. This inconsistency probably was due to the employment of only one single case $(j>i$ or $j<i)$ and the generation of only "half" of intact contour map (for instance, only $\mathrm{AD}$ or $\mathrm{BD}$ as shown in Table 2). Our results shown the SRs performed either identically or even better than NDVIs for estimating the LCC of summer barley. The most significant difference between the contour maps of NDVIs and SRs is that the former yield, for the two cases of $j>i$ and $j<i$ together, diagonal symmetrical images (Fig. 1). It is consistent with the investigations for selecting NDVIs and the "second soil adjusted vegetation index" SAV2 (Darvishzadeh et al., 2008; Tian et al., 2011). In contrast, contour maps of SRs differed greatly from one another in different cases of $j>i$ and $j<i$ (Fig. 1). For instance, the best SR for the variety Iron was identified below the diagonal, as well as the best SR for all varieties (Fig. 1, Table 2). This suggests that the best SR in a contour map for a different variety can be in different sides of the diagonal, above or below the diagonal. However, one best NDVI in the contour map normally has an "inverted" form (see Table 2) with the same bands and the same predictive ability. Consistence can also be found in previous studies (Darvishzadeh et al., 2008; Tian et al., 2011). Therefore, selecting two-bands combinations improves the performance of SRs and NDVIs for estimating LCC. SRs seem to be the best indicators (of two-bands combinations) and NDVIs seem to be good alternatives for SRs.

A contour map of wavelengths ranging from $350-1800 \mathrm{~nm}$ is not very commonly seen in literatures. Our results indicate that combinations of the wavelengths at $600-700 \mathrm{~nm}$ paired with the wavelengths at $1000-1350 \mathrm{~nm}$ or $1600-1800 \mathrm{~nm}$ can also yield high $\mathrm{R}^{2}$ values (0.6-0.8). This provides a visual understanding that not only the empirical wavelengths region but also the longer wavelengths region are effective for estimating LCC using the two-bands combinations as SR and NDVI. Moreover, most researchers generally do not consider spectral data of wavelengths shorter than $400 \mathrm{~nm}$ because of noise ( $\mathrm{Li}$ et al., 2010). However, our results reveal that SRs and NDVIs with the Ultraviolet bands can also be selected as the best indicators for LCC. The consistence can be found in previous studies (Read et al., 2002; Li et al., 2010). This may improve our knowledge base for developing new VIs and crop sensors using longer wavelengths. Since the spectral data is often influenced by many factors (soil background, LAI, species, growth stages etc.), it still needs to be further evaluated.

\section{CONCLUSIONS}

This study was conducted in a multi-varieties summer barley field without artificial nutrient gradients. Using a more comprehensive computing method of "correlation matrix", newly selected SRs are competent indicators of LCC and may outperform NDVIs. Selecting optimal two-bands combinations strengthened the relationships between spectral indices and LCC as compared with those empirical combinations (Green, Red and NIR) and indices published for estimating chlorophyll. Moreover, Ultraviolet, Violet and Blue bands are more effective for estimating the LCC in a single variety, whereas Red-edge bands are more efficient for that across all varieties. The overall performances of both newly selected VIs and published VIs are significantly influenced by the varieties. In present study, we are the first to our knowledge to compare the difference of the two cases $(j>i$ and $j<i$ ) for computing and selecting the SRs. Our work was inspired by many previous researches, and shall be a contribution to the knowledge base of hyperspectral remote sensing. However, it remains to be further validated in our future work with more datasets involving different years, varieties, species, locations, etc. 


\section{REFERENCES}

Asrar, G., Kanemasu, E.T. and Yoshida, M., 1985. Estimates of leaf area index from spectral reflectance of wheat under different cultural practices and solar angle. Remote Sens. Environ., 17(1) pp. 1-11.

Blackburn, G.A., 1998. Quantifying chlorophylls and carotenoids at leaf and canopy scales: An evaluation of some hyperspectral approaches. Remote Sens. Environ., 66(3) pp. 273-285.

Carter, G.A. and Knapp, A.K., 2001. Leaf optical properties in higher plants: linking spectral characteristics to stress and chlorophyll concentration. Am. J. Bot., 88(4) pp. 677-684.

Chappelle, E.W., Kim, M.S. and McMurtrey III, J.E., 1992. Ratio analysis of reflectance spectra (RARS): An algorithm for the remote estimation of the concentrations of chlorophyll A, chlorophyll B, and carotenoids in soybean leaves. Remote Sens. Environ., 39(3) pp. 239-247.

Darvishzadeh, R. et al., 2008. LAI and chlorophyll estimation for a heterogeneous grassland using hyperspectral measurements. Isprs J. Photogramm., 63(4) pp. 409-426.

Dash, J. and Curran, P.J., 2004. The MERIS terrestrial chlorophyll index. Int. J. Remote Sens., 25(23) pp. 54035413.

Daughtry, C.S.T., Walthall, C.L., Kim, M.S., de Colstoun, E.B. and McMurtrey III, J.E., 2000. Estimating corn leaf chlorophyll concentration from leaf and canopy reflectance. Remote Sens. Environ., 74(2) pp. 229-239.

Gamon, J.A., Peñuelas, J. and Field, C.B., 1992. A narrowwaveband spectral index that tracks diurnal changes in photosynthetic efficiency. Remote Sens. Environ., 41(1) pp. 35-44.

Gitelson, A.A. and Merzlyak, M.N., 1996. Signature analysis of leaf reflectance spectra: Algorithm development for remote sensing of chlorophyll. J. Plant Physiol., 148(3-4) pp. 494500 .

Gitelson, A.A., Gritz, Y. and Merzlyak, M.N., 2003. Relationships between leaf chlorophyll content and spectral reflectance and algorithms for non-destructive chlorophyll assessment in higher plant leaves. J. Plant Physiol., 160(3) pp. 271-282.

Haboudane, D., Miller, J.R., Pattey, E., Zarco-Tejada, P.J. and Strachan, I.B., 2004. Hyperspectral vegetation indices and novel algorithms for predicting green LAI of crop canopies: Modeling and validation in the context of precision agriculture. Remote Sens. Environ., 90(3) pp. 337-352.

Haboudane, D., Miller, J.R., Tremblay, N., Zarco-Tejada, P.J. and Dextraze, L., 2002. Integrated narrow-band vegetation indices for prediction of crop chlorophyll content for application to precision agriculture. Remote Sens. Environ., 81(2-3) pp. 416-426.

Hansen, P.M. and Schjoerring, J.K., 2003. Reflectance measurement of canopy biomass and nitrogen status in wheat crops using normalized difference vegetation indices and partial least squares regression. Remote Sens. Environ., 86(4) pp. 542-553.

Jordan, C.F., 1969. Derivation of leaf-area index from quality of light on the forest floor. Ecology, 50(4) pp. 663-666.

Lancashire, P.D. et al., 1991. A uniform decimal code for growth stages of crops and weeds. Ann. Appl. Biol., 119(3) pp. 561-601.

Li, F. et al., 2010. Evaluating hyperspectral vegetation indices for estimating nitrogen concentration of winter wheat at different growth stages. Precis. Agric., 11(4) pp. 335-357.

Peñuelas, J., Gamon, J.A., Fredeen, A.L., Merino, J. and Field, C.B., 1994. Reflectance indices associated with physiological changes in nitrogen- and water-limited sunflower leaves. Remote Sens. Environ., 48(2) pp. 135-146.

Read, J.J., Tarpley, L., McKinion, J.M. and Reddy, K.R., 2002. Narrow-waveband reflectance ratios for remote estimation of nitrogen status in cotton. J. Environ. Qual., 31(5) pp. 1442-1452.

Rouse, J.W., Haas, R.H., Schell, J.A. and Deering, D.W., 1974. Monitoring vegetation systems in the great plains with ERTS, In: Third ERTS Symposium, NASA SP-351, Vol. 1. NASA, Washington, DC, pp. 309 - 317.

Sims, D.A. and Gamon, J.A., 2002. Relationships between leaf pigment content and spectral reflectance across a wide range of species, leaf structures and developmental stages. Remote Sens. Environ., 81(2-3) pp. 337-354.

Stroppiana, D., Boschetti, M., Brivio, P.A. and Bocchi, S., 2009. Plant nitrogen concentration in paddy rice from field canopy hyperspectral radiometry. Field Crops Res., 111(1-2) pp. 119-129.

Thenkabail, P.S., Smith, R.B. and De Pauw, E., 2000. Hyperspectral vegetation indices and their relationships with agricultural crop characteristics. Remote Sens. Environ., 71(2) pp. 158-182.

Tian, Y.C. et al., 2011. Assessing newly developed and published vegetation indices for estimating rice leaf nitrogen concentration with ground- and space-based hyperspectral reflectance. Field Crops Res., 120(2) pp. 299-310.

Xue, L., Cao, W., Luo, W., Dai, T. and Zhu, Y., 2004. Monitoring leaf nitrogen status in rice with canopy spectral reflectance. Agron. J., 96(1) pp. 135-142.

Yoder, B.J. and Pettigrew-Crosby, R.E., 1995. Predicting nitrogen and chlorophyll content and concentrations from reflectance spectra (400-2500 nm) at leaf and canopy scales. Remote Sens. Environ., 53(3) pp. 199-211.

Zarco-Tejada, P.J., Miller, J.R., Noland, T.L., Mohammed, G.H. and Sampson, P.H., 2001. Scaling-up and model inversion methods with narrowband optical indices for chlorophyll content estimation in closed forest canopies with hyperspectral data. IEEE T. Geosci. Remote, 39(7) pp. 14911507.

Zhao, D., Raja Reddy, K., Kakani, V.G., Read, J.J. and Carter, G.A., 2003. Corn (Zea mays L.) growth, leaf pigment concentration, photosynthesis and leaf hyperspectral reflectance properties as affected by nitrogen supply. Plant Soil, 257(1) pp. 205-218.

Zhao, D., Reddy, K.R., Kakani, V.G. and Reddy, V.R., 2005b. Nitrogen deficiency effects on plant growth, leaf photosynthesis, and hyperspectral reflectance properties of sorghum. Eur. J. Agron., 22(4) pp. 391-403.

Zhao, D., Reddy, K.R., Kakani, V.G., Read, J.J. and Koti, S., 2005a. Selection of optimum reflectance ratios for estimating leaf nitrogen and chlorophyll concentrations of field-grown cotton. Agron. J., 97(1) pp. 89-98.

Zhu, Y., Zhou, D., Yao, X., Tian, Y. and Cao, W., 2007. Quantitative relationships of leaf nitrogen status to canopy spectral reflectance in rice. Aust. J. Agr. Res., 58(11) pp. 1077-1085.

\section{ACKNOWLEDGEMENTS}

Part of this study was supported by the BMBF founded CropSense project (www.cropsense.de). We thank Thomas Schuhmacher, Christian Jekel, Christoph Hütt and the staffs of INRES-Horticultural Science for carrying out the measurements of reflectance and LCC. Special thanks to both anonymous reviewers for the constructive comments on this paper. 